\title{
Standard Conduits Used in Coronary Artery Revascularisation, an Immediate and Midterm Patency Comparative Study in the Population of Largest City of Uttar Pradesh, A Single Centre Study
}

\author{
Yadav GD 1 , Satsangi A $^{2 *}$ and Singh $B^{3}$ \\ ${ }^{1}$ Department of general surgery, GSVM medical college, Kanpur, India \\ 2Department of general surgery, GSVM medical college Kanpur, India \\ ${ }^{3}$ Department of general surgery, GSVM medical college Kanpur, India
}

\section{Research article \\ Volume 2 Issue 3}

Received Date: June 01, 2018

Published Date: June 15, 2018

${ }^{*}$ Corresponding author: Amitabh Satsangi, Junior resident third year department of general surgery, GSVM medical college and associated llr hospital, swaroopnagar, Kanpur 208002, India, Tel: +91 6393099608; Email: amoeba418@gmail.com

\section{Abstract}

Introduction: Coronary artery revascularisation is a mainstay technique to alleviate the morbidity of coronary artery disease. There are various conduits available for coronary bypass grafting, we hereby study the conduits routinely used for revascularisation and compare the results.

Material and methods: In study 56 people were included, who visited the OPD, were in the IPD, or had come for follow up in OPD over a period of 1 year .Patient included in the study were cases of coronary artery disease in which CABG was a class I indication. A total of 215 conduits were grafted, which included left internal mammary artery graft, reversed saphenous vein graft, radial artery grafts and patients were evaluated for graft patency over a period of 1 year at intervals of 1 month and 1 year.

Results: There were 56 LIMA grafts used, 150 RSVG and 9 RA grafts grafted. During follow up period the data was divided into graft failures (defined as total occlusion of the graft), graft failures that took place within 1 months of grafting were termed as early graft failure and graft failures that took place after 1 year were termed as intermediate graft failure. Out of 215 conduits that were grafted a total of 26 conduits were considered as graft failures over a period of 1 year.

Conclusion: Reversed saphenous grafts had a greater graft occlusion rate in comparison to internal mammary graft and were better suited for non- LAD site for grafting and thus routinely practiced. Radial artery theoretically seemed to be a better option than RSVG but in our study the data was insufficient to come to a conclusion.

Keywords: Revascularisation; Cardiovascular Diseases; Descending Artery; Saphenous Vein 


\section{Open Access Journal of Cardiology}

Abbrevations: CABG: Coronary Artery Bypass Surgery; RSVG: Reverse Saphenous Vein Graft; ACC: American College Of Cardiology; LV: Left Ventricular.

\section{Introduction}

Coronary revascularisation has come a long way from its humble beginning as an experimental approach in the hands of Dr Alexis Carrel about a century ago. The great economical divide In India has rendered the nation susceptible to a wide spectrum of diseases, from infectious diseases to non-communicable diseases including cardiovascular diseases. Cardiovascular diseases have encroached and disabled the functioning population of India, becoming the leading cause of mortality [1]. Indian population is affected as much as a decade earlier in comparison to their western counterpart $[2,3]$. In present scenario, coronary artery bypass surgery (CABG) has proven to be most effective and best therapy for ischemic heart disease. In our study we have tried to make a small contribution in the plethora of data that is available on the various conduits used in coronary revascularisation. We compare the use of left internal mammary artery, reverse saphenous vein graft (RSVG) and radial artery for coronary artery revascularisation, pertaining to their immediate and intermediate term patency in the largest city of Uttar Pradesh (Kanpur) Left internal mammary artery was mainly used for revascularisation of left anterior descending artery because of its known benefits at this particular site. RSVG and radial artery were used for grafting Right coronary artery, Left circumflex artery, the obtuse marginal branch, diagonal branch, posterior descending artery, ramus intermedius.

\section{Material and Method}

\section{Source of Data}

All patients older than 18 years admitted in our department with coronary artery disease from Dec. 2015 to Oct 2017 were including in the study following procedure.

\section{Inclusion criteria - patients having following criteria were included in the study}

- Coronary artery disease.

- Further patients with class 1 indications for CABG were included in the study.
Class I indications for CABG from the American College of Cardiology (ACC) and the American Heart Association (AHA) are as follows [4].

- Left main coronary artery stenosis $>50 \%$.

- Stenosis of proximal LAD and proximal circumflex $>70 \%$.

- 3-vessel disease in asymptomatic patients or those with mild or stable angina.

- 3-vessel disease with proximal LAD stenosis in patients with poor left ventricular (LV) function.

- 1- or 2-vessel disease and a large area of viable myocardium in high-risk area in patients with stable angina.

- $>70 \%$ proximal LAD stenosis with either ejection fraction $<50 \%$ or demonstrable ischemia on noninvasive testing.

\section{Exclusion Criteria - Patients having Following Criteria} will not be Included in the Study

- Age $>80$ years.

- Unstable angina or myocardial infarction $<2$ and $<7$ days before surgery, respectively.

- Previous or concurrent cardiac surgery.

- Need for continued antithrombotic drug therapy; an increased risk of bleeding; impaired renal or hepatic function.

- Inability to repeat coronary angiography due to allergy to contrast agent.

- Cardiogenic shock.

\section{Type of Study}

The present study is prospective study.

\section{Collection of Data}

The study was conducted on the hospital based time bound in all those cases who satisfied the inclusion criteria. The data was collected from detailed history, clinical examination, and investigations (haematological investigations and radiological parameters) on the patients.

\section{Period of Follow Up}

- OPD basis in patients .

- IPD basis. 


\section{Open Access Journal of Cardiology}

- Patients were evaluated during the hospital stay, then on 1 month and 1 year or observed if presenting with complications.

\section{Methods}

A written informed consent was taken from all the patients for inclusion in the study and ethical clearance was achieved. The patients were told about the follow up schedule. A thorough epidemiological data about patient were recorded. All the routine investigation and radiological investigation were preserved for the future reference. In the various group, the patients included in study were followed up and studied for patency of the various graft materials using following imaging modalities - CT angiography

- Conventional Coronary Angiography

The purpose of the study is to compare the various conduits generally used in practice for revascularization and their functioning over a period of 1 year, prospectively, irrespective of their site of grafting. Graft failure is considered when there is either recurrence of initial symptoms which can be attributed to the dysfunctioning of a particular conduit, or direct imaging of the conduit which states its occlusion. Stenosis of the conduit was not considered as criteria until and unless there was complete occlusion of the conduits.

After the documentation of conduit occlusion / graft failure, the subjects were not further followed. For the internal mammary artery grafts, attention was paid to any large side branches and associated attenuation of the distal internal mammary artery lumen. The graft flow was considered poor only if the diameter of the distal internal mammary artery was less than two-thirds of the proximal and measured less than the grafted coronary artery. The condition of the internal mammary artery graft was considered excellent if the lumen was smooth, with the distal diameter greater than $2 \mathrm{~mm}$, and there was good filling of the grafted coronary artery.

\section{Follow-Up Observation}

The study population was meticulously followed up over a period of 1 year. Patient included in the study were cases of coronary artery disease in which CABG was a class I indication During the study diabetes and hypertension were taken as consistent co-morbidities that have a proven role in disease causation and progression and directly affect the conduits used and their future outcomes as conduits used at our centre were mainly autologous conduits harvested from the patient's body [4] (Tables $1 \& 2$ ).

\begin{tabular}{|c|c|}
\hline Number of patients & $\mathbf{5 6}$ \\
\hline Gender distribution & Male(52)/Female(4) \\
\hline Comorbidities & $\mathrm{DM}(36 \%) / \mathrm{HTN}(41 \%) /$ Both \\
$(23 \%)$
\end{tabular}

Table 1: Patients' characteristic at the time of admission.

\begin{tabular}{|c|c|c|c|c|}
\hline Age Group & $\mathbf{4 0 - 4 9}$ & $\mathbf{5 0 - 5 9}$ & $\mathbf{6 0 - 6 9}$ & $\mathbf{7 0 - 8 0}$ \\
\hline Number Of Subjects & 15 & 21 & 15 & 5 \\
\hline
\end{tabular}

Table 2: Age distribution.

In our institution, for the purpose of revascularisation of the coronary artery, the grafts most frequently used were as following:

- Left internal mammary artery (LIMA).

- Reversed saphenous vein graft (RSVG).

- Radial artery (RA).

In this study, in the study group of 56 patients a total of 215 conduits were grafted, which included left internal mammary artery graft, reversed saphenous vein graft, radial artery graft. At our institution LIMA was used mostly to graft the left anterior descending artery (LAD), in this study population all the LIMA grafts were grafted upon the LAD. RSVG and radial artery were used for grafting Right coronary artery, Left circumflex artery, the obtuse marginal branch, diagonal branch, posterior descending artery, ramus intermedius. Other grafts like right internal mammary artery, right gastro-epiploic artery, and inferior epigastric artery were not used. Over a period of 1years patients were followed up and imaging was done after 1 months and 1 year time period or when the patient was presenting with symptoms suggestive of graft failure. During follow up period the data was divided into graft failures (defined as total occlusion of the graft), graft failures that took place within 1 months of grafting were termed as early graft failure and graft failures that took place after 1 year were termed as intermediate graft failure. Out of 215 conduits that were grafted a total of 26 conduits were considered as graft failures over a period of 1 year.

Early graft failure (at 1 month) was seen in 8(3.8\%) patients of which six were vein grafts and LIMA was affected in 2 instances. Thus out of 56 LIMA conduits, $2(3.57 \%)$ showed evidence of early failure. During the 


\section{Open Access Journal of Cardiology}

study 9 radial artery grafts grafted were followed and over a period of 1 month no graft failure was appreciated, hence there were no early graft failure observed. After a follow up of complete 1 year the data observed was that out of the 54 remaining LIMA, 2 graft failures were recorded. They were recorded after a period of 1 year and thus termed as intermediate graft failure (Table 3 ).

\begin{tabular}{|c|c|c|}
\hline & $\begin{array}{c}\text { Intermediate Graft } \\
\text { Failure }\end{array}$ & $\begin{array}{c}\text { Total number of } \\
\text { grafts }\end{array}$ \\
\hline LIMA & 2 & 54 \\
\hline
\end{tabular}

Table 3: Intermediate Graft Failure/ Total number of grafts.

Out of the 150 RSVG that were grafted , 6 had early graft failure, the remaining 144 grafts were followed up and out of them 12 were found to have failed over the period of 1 year from grafting and labelled as intermediated graft failure. In case of radial artery a total of 9 grafts were grafted out of which 2 grafts failed after a period of 1 year, thus intermediate graft failure of 2 grafts were noted. Over a period of 1 year it was observed that out of total 56 LIMA's grafted 4 had failed, Out of 150 RSVG grafted 18 had failed and out of 9 RA grafted 2 grafts had failed (Table 4).

\begin{tabular}{|c|c|c|c|}
\hline & Graft Failure & Total Grafts & Failure Percent \\
\hline LIMA & 4 & 56 & $7.14 \%$ \\
\hline RSVG & 18 & 150 & $12 \%$ \\
\hline RA & 2 & 9 & $22 \%$ \\
\hline
\end{tabular}

Table 4: Graft Failure/ Failure Percent.

\section{Discussion}

In our study we addressed the mammoth problem of coronary artery disease, which include the follow up study of 56 patients undergoing operative interventions for various degrees of coronary circulation. Gupta R, et al. in their study discussed the rampant epidemic of the coronary heart disease in India and observed a rise of total adult deaths attributed to coronary heart disease from $26 \%$ in 2001 to $32 \%$ in 2013 [5]. Their study made the gravity of this grave situation of vascular disorders crystal clear.

We compared the common conduits for coronary revascularisation to know which is superior than its counterparts in terms of providing a long symptom free period post -operatively to the patient. It is quite baffling to know that even after half a decade of coronary artery bypass grafting still there are no clear guidelines for which conduits to be used for revascularisation. Longterm conduit patency is the key factor for the success of the procedure though through a plethora of studies we are realising the superior results provided to us by an arterial conduit as compared to a venous conduit. The clinical benefits of using arterial conduits namely internal mammary arteries as well as radial arteries are well established now and provide a better and longer symptom free post-operative period. This has been proven an geographically in our study as well as various national and international studies discussed later on. In our study in case of coronary revascularisation, a total of 215 conduits were grafted, which included 56 left internal mammary artery , 150 reversed saphenous vein grafts , 9 radial artery as conduits to various arteries of coronary circulation.

In the past 50 years there has been extensive scrutiny upon the various grafts used for revascularisation and to search for the ideal graft. Through past studies we have come to accept the superior functioning of the arterial grafts in comparison to their venous counterparts [6-8]. In our study RSVG showed a patency of $88 \%$ after a period of 1 year. In concordance with various national and international publications it was noticed that Left internal mammary artery has a better patency in comparison saphenous vein graft [6,7]. The saphenous vein (SPV) is a commonly used conduit for bypass due to the ease of harvest, which can generally be done through minimally invasive procedures, with less scarring and faster recovery. But the failure of vein grafts over the long term remains a significant problem.

The saphenous vein (SPV) is a commonly used conduit for bypass due to the ease of harvest, which can generally be done through minimally invasive procedures, with less scarring and faster recovery. But the failure of vein grafts over the long term remains a significant problem. Reasons for elevated failure rates include variable quality and size of the veins, the presence of valves within the veins and the potential for areas of dilatation (varicosities) within the veins. These and other factors can lead to flow pattern disturbances within the veins that can lead to early failure. Though there are many problems with saphenous vein graft but it still remains one of the cardinal components of coronary revascularisation especially with the extensive kind of coronary disease being dealt with, which renders one to use multiple grafts and the paucity of the arterial grafts. 


\section{Open Access Journal of Cardiology}

\section{Conclusion}

On the basis of observation of the clinical profiles of the cases with the evaluation of the various conduits by radiological methods mainly angiography and duplex scan the following conclusions were drawn:

- Maximum of our cases of coronary artery disease were in the age group of 50-59 years.

- In case of the coronary circulation Internal mammary artery mainly the Left internal mammary artery and its use as a conduit to the Left anterior descending artery has the best patency rate in comparison to radial artery graft as well as the reversed saphenous vein graft.

- Reversed saphenous grafts had a greater graft occlusion rate in comparison to internal mammary graft and were better suited or non- LAD site for grafting and thus routinely practiced

- Radial artery theoretically seemed to be a better option than RSVG but in our study the data was insufficient to come to a conclusion.

There is a significant variety of vascular conduits options for coronary bypass surgery. Adequate graft selection is the most important factor for the success of the intervention. To ensure durability, permeability, and bypass function, there must be a morphological similarity between the graft and the coronary artery. Currently, the internal thoracic artery is the standard choice for bypass surgery because of the morphological characteristics of the wall that makes less prone to developing atherosclerosis and hyperplasia. The radial and right gastroepiploic arteries are the following second and third best options, respectively.

\section{Ethical Approval}

"All procedures performed in studies involving human participants were in accordance with the ethical standards of the institutional and/or national research committee and with the 1964 Helsinki declaration and its later amendments or comparable ethical standards."

\section{Informed Consent}

"Informed consent was obtained from all individual participants included in the study."

\section{Conflict of Interest}

Author 1, Author 2, Author 3 and Author 4 declare that they have no conflict of interest.

\section{References}

1. Reddy SK, Shah B, Varghese C, Ramadoss A (2005) Responding to the threat of chronic diseases in India. Lancet 366(9498): 1744-1749.

2. Joshi P, Islam S, Pais P, Reddy S, Dorairaj P, et al. (2007) Risk factors for early myocardial infarction in South Asians compared with individuals in other countries. JAMA 297(3): 286-294.

3. Xavier D, Pais P, Devereaux PJ, Xie C, Prabhakaran D, et al. (2008) Treatment and outcomes of acute coronary syndromes in India (CREATE): a prospective analysis of registry data. Lancet 371(9622): 1435-1442.

4. Hillis LD, Smith PK, Anderson JL, Bittl JA, Bridges CR, et al. (2012) 2011 ACCF/AHA guideline for coronary artery bypass graft surgery: executive summary: a report of the American College of Cardiology Foundation/American Heart Association Task Force on Practice Guidelines. J Thorac Cardiovasc Surg 143(1): 4-34.

5. Gupta R, Guptha S, Sharma KK, Gupta A, Deedwania P (2012) Regional variations in cardiovascular risk factors in India: India Heart Watch. World J Cardiol 4(4): 112-120.

6. Bassri H, Salari F, Noohi F, Motevali M, Abdi S, et al. (2009) Evaluation of early coronary graft patency after coronary artery bypass graft surgery using multislice computed tomography angiography. BMC Cardiovascular Disorders 9: 53.

7. Boylan MJ, Lytle BM, Loop FD, Taylor PC, Borsh JA, et al. (1994) Surgical treatment of isolated left anterior descending coronary stenosis. Comparison of left internal mammary artery and venous autograft at 18 to 20 years of follow-up. J Thorac Cardiovasc Surg 107(3): 657-662.

8. Fitz Gibbon GM, Kafka HP, Leach AJ, Burton JR (1996) Interventions for coronary stenosis. A Canadian experience of 30 revolutionary years. Can J Cardiol 12(10): 893-900. 